\title{
XXII. On elasticity. An Essay read before the Askesian Society in the Session 1802-3
}

\section{Alexander Tilloch}

To cite this article: Alexander Tilloch (1805) XXII. On elasticity. An Essay read before the Askesian Society in the Session 1802-3, Philosophical Magazine Series 1, 22:86, 138-152, DOI: $10.1080 / 14786440508676759$

To link to this article: http://dx.doi.org/10.1080/14786440508676759

曲 Published online: 18 May 2009.

Submit your article to this journal

Џll Article views: 3

Q View related articles $\sqsubset$ 
Fig. 2. The animal of its natural size, the belly upwarus.

Fig. 3. Under part of the head as seen in a strong light, by means of which not only the outward but also the inward direction of its members is discernible : thus we see the roots of the antennæ join together and communicate with the two great canals $a a$, which carry the blood to all the parts; and $\mathrm{I}$ am persuaded the forceps join issue there too; but the parts are too glandular to allow of this being distinctly seen.

Besides, upon the creature eating some mackrel liver, a great quantity of blood was discharged from the under fissures near the tips of these forceps a great number of times. Meeting with a medium of nearly the same density as itself (i.e. the water), it diffuses itself in the form of a thick smoke issuing from a furnace chimney when fresh fuel is added; after which the forceps became so close that no magnifier I could use upon him would enable me to see them : yet this affords a presumption that they are each a kind of proboscis. Some blood was discharged from the mouth at the same time.

Fig. 4. The eye of its natural size.

Fig. 5. The same magnified.

London, 215, Tooley-street, 20th June 1805.

XXII. On Elasticity. By Alexander Tilloch. An Essay read Uefore the Askesian Society in the Session 1802-3.

$\mathbf{I}_{\mathbf{T}}$ is not my intention in the present paper to enter upon any inquiry respecting the laws by which elasticity acts, as they have often been investigated already, and are well known to every one acquainted with the first elements of mechanics. I mean merely to confine myself to a few thoughts on the physical cause of elasticity, or that property of bodies which enables them, after any external pressure, to restore themselves to their former figure.

The cause of elasticity has been proposed to be accounted for in various ways. The Cartesians held that it was a necessary consequence of their materia subtilis, or matter of the second element, making an effort to pass through pores too narrow for it. Thus, when a straight elastic body is bent by any force, the pores become contracted on the concave side, and, if they were before spherical, become for instance elliptical, or of some other form; and the materia subtilis, 
subtilis, hindered in its attempt to pass, makes an effort to restore the body to its first state. In this theory there is something like the effort of a strong mind when first seizing upon a new truth, and endeavouring to reduce it to a dependence on and connection with known or admitted facts; but the defects in the reasoning ought to have convinced its supporters, that a more satisfactory way of accounting for the phænomenon was still a desideratum. It must be obvious to any person who will take the trouble to analyse the argument, that if the materia subtilis in a spherical cavity could by pressure (being hindered at the same time from passing off) accommodate itself to the same cavity rendered elliptical, that in doing so it has in fact become smaller in volume than it was before. The materia subtilis is thus assumed to be compressible; and, as it makes an effort to restore the body, or, in other words, its cavities, to the first form, it is assumed to be expansive. But what does this amount to ? Merely that a body is elastic because it contains elastic matter.

Other philosophers, disliking the materia sultilis of the Cartesians, have adopted an ethereal medium. Their mode of reasoning, however, is so similar to that of the former, that they leave the mind as unsatisfied as before. Indeed, the mere change of a name can throw no new light upon the subject.

Some account for elasticity by supposing that when an elastic body is bent or compressed a number of little vacuities are formed in it, and that on removing the force the pressure of the atmosphere, endeavouring to destroy the vacuities thus formed, restores the body to its first frgure. This doctrine, however plausible, is inadmissible, if for 10 other, for this one reason:-Many bodies require a greater force to bend them to any given degree than can be found by multiplying the number of square inches in their surface by 14 pounds, the force exerted by the atmosphere on a square inch; besides, the phænomena of elasticity manifest themselves in vacuo.

Others assume that all bodies contain air in their vacuities, and ascribe their elastic property to that of the air inclosed in them. This is little more than a substitution of air for the materia subtilis, and the ether assumed by others. But whence has air itself the property of elasticity? This is a part of the general inquiry, and as necessary to be solved as the source whence other bodies derive the same property.

Others account for elasticity from the law of attraction, applied 
applied with so much success, since the time of Newton, to the solution of many other of the phrnomena of nature; and we are inclined to think that the more this subject is investigated the more will it appear that it acts an important part in producing those effects ascribed to elasticity. According to this theory, when an elastic body is struck or bent so that the component parts, or portions of them, are moved a little from each other, but not beyond their spheres of attraction, they must, on the cessation of the applied force, spring back to their natural state.

Repulsion also has been held to be the cause of elasticity in the case of aëriform fluids, and this repulsion is ascribed to the presence of heat. In this case repulsion is not made use of as the last term of our knowledge, but merely as expressive of a certain state of action ascribed to another cause. Some, however, make use of the expression without so defining it, and, if they mean any thing at all, use it to express an abstract property of which they know not the cause. We may therefore observe, in passing, that this term should be used as seldom as possible in philosophical subjects, and never unless the author has defined the sense in which he employs it.

Angther theory has been proposed, which has been admitted by many as sufficient to account for all the phænomena, not of the elasticity of bodies only, but of matter in general. This theory, which has the celebrated Boscovich for its author, supposes that the whole matter of the universe consists of a great but finite number of simple, indivisible, INEXTENDED atoms, endued with repulsive and at tractive forces, which vary and change from the one to the other according to circumstances pointed out in his System of Natural Philosophy, of which a good account may be seen in the Supplement to the Encyclopeedia Britannica, under Boscavich. The most singular part of the system is, that his atoms, in their least and innermost distances, repel each other, and this power of repulsion increases as the distances are diminished: in sensible distances they attract each other, and this power decreases as the squares of the distances increase, constituting universal gravity : between the innermost repulsive force and the outermost attractive one, in the insensible distances, many varieties occur; at a certain distance the repulsive force vanishes-increase that distance, and attraction begins, increases, lessens, and vanishes, till, at a certain increase of distance, the force becomes repulsive; and so on alternateiy, always changing from the one to the other with the increased distances; sometimes more slowly, 
slowly, sometimes more rapidly, and sometimes one of the forces may come to nothing and then return back to the same kind without passing to the other. And for all this, it seems, there is full room in the distances that are INSENSIBLE to us, seeing the least part of space is divisible in infinitum.

Assuming all this, and exhibiting a curve and other necessary appendages to assist the mind in comprehending his theory, the anthor applies it to explain all the phænomena of the material universe, assuming also in his progress such forms and arrangements as are required to make the system apply to the properties possessed by matter in those modifications which distinguish and divide it into classes: thus solid bodies are formed of parallelopipides, fibres, and of irregular figures, occasioning a greater cohesion than in fluids, and preventing the motion of the parts round one another; so that when one part is moved the rest follow. Those bodies whose particles are placed in limits which have strong repulsive arches within them are harder; those are softer whose particles have those arches of repulsion weaker. When the particles are placed in limits that have weak arches of repulsion and attraction on each side, the body is flexible; and, if those arches are short, the particles may come to new limits of cohesion, and remain bent: but if the arches are longer the repulsion and attraction may act, and restore the body to its former position; nay, in doing this with an accelerated velocity, the parts will pass their former limits, and then vibrating backwards and forwards exhibit that effect which is called elasticity.

On this theory we shall only observe, that whatever conviction it may carry to minds habituated to profound mathematical investigations, it can convey but little information to a man who merely aims at a knowledge of the properties of matter, as consisting, not of inexiended atoms, but of such molecula as occupy sensible space. What the wiser is such a man for being told that certain forces exist, and that some idea may be formed of their mode of operating by conceiving them to act in the directions of certain curves, and with powers varying according to circumstances? He may assent to thiz; but as bis weak mind can conceive nothing of matter inextended, either in itself or in its atoms, be cannot consider his difficulties as solved by merely having them stated to him in a new form; for to him the whole of this system appears to be no more at best but a regular mathematical statement of those operations of matter, the causes of which he still wishes to explore. 
C. Barruel has proposed a theory different in some respects from any of those $I$ have mentioned,-more in appearance, however, than in reality. He contends that caloric acts a great share in the phænomena of elasticity, and maintains that it is itself elastic in consequence of the property which the moleculæ of this fluid have of repelling each other: a property, he says, the more probable as it is observed in the electric fluid, with which caloric has so great an analogy. "In a word," says Barruel, "we may be satisfied with admitting its elasticity as a fact from which we may set out as from an incontestable principle." To enter at great length into this theory, an account of which may be seen in the sixth volume of the Philosophical Magazine, p. 52, would encroach too much on our present time. The author presents, in his memoir on this subject, some curious thoughts, and well worthy of a perusal. It is only necessary here, however, to state in few words the substance of his reasoning. 1st, Every body in nature is porous, and these pores are proportioned to the density of the substance: 2d, These pores are filled with different fluids, and principally with caloric. But caloric possesses a strong repulsive force; from which it follows, that, when an elastic body is compressed, the caloric in its pores drives back, by its repulsive power, the displaced parts, and brings them to their former state.

On this theory it may be observed, that however true it may be that caloric acts a distinguishing part in the phænomena of elasticity, the author seems to have made hardly any other use of the fact than to put that substance in the place of the materia subtilis and ether of the earlier philosophers. He assumes too that it necessarily possesses elasticity; but he ought either to have first proved it, or at least to have demonstrated, that if that property be not inherent in caloric, there could be no elasticity in other matter. In short, were it even proved that caloric is naturally and essentially elastic, and the cause of elasticity in other matter, still the main question would remain unsolved, which would then be-What is the physical cause of elasticity in caloric?

Libes makes elasticity to depend on caloric interposed either between the moleculæ of bodies or combined with them, and at the same time on the attractive force of these moleculæ. "This being premised," says he, "I say that the restoration of solid bodies after compression is a combined effect, which depends in part on the repulsive force which their integral moleculæ have received from caloric, 
loric, and in part from the attractive force of these moleculæ."”

I should have been glad to have been able to have given something more of Libes's theory than this short notice, especially as this little seems to approach nearer to my ideas of the true theory than any thing I have yet noticed; but I know not in what work it is given. This notice is from the Journal de Physique, vol. 1. p. 10. an 8.

Thus have I given a short account of all the theories that have been advanced to account for the phænomena of elasticity.; or, at least, of all I recollect worthy of notice. Some of them, we have seen, in passing, fall entirely short of the object they aim at, and are therefore unworthy of further notice. In others, however, the mode of argument is so well managed, that had their authors attended to a single fact or two, which they have overlooked, it is probable that the subject would, before this time, have received that full elucidation of which I believe it is capable.

Like those who hare gone before me, I may fail in the task I have imposed upon myself; but $I$ hope to avoid inconsistency or unfair assumptions. It does not appear necessary to admit even that elasticity belongs to matter considered simply. Indeed, I think the contrary is the fact. But that my meaning may not be mistaken, I shall explain in as few words as possible this part, which may be considered as fundamental, of the doctrine I mean to propose, By simple matter I mean the primitive moleculæ, or atoms, of which bodies are formed. However complex may be the state in which we find bodies, they consist of elementary principles, which principles themselves are formed perhaps of others, but ultimately of inelastic atoms of simple matter. Let us, for example, take some matter considered as simple and elementary, say caloric, I would affirm of it that it is not necessarily elastic; and so of any other simple matter.

But if elasticity be not essentially necessary to matter considered simply, whence do bodies derive that property? I answer, From the same source whence they derive almost every other quality that belongs to them-from their composition and internal arrangement.

I would bave said ALL their qualities, instead of limiting the expression to almost all of them, but that they possess one property which may, and probably does, depend on some other cause, I mean that of attraction. Of the cause of this we know nothing; but its existence and the laws by which it acts being known, philosophers do not fail to avai! themselvss 
themselves of them in explaining those phænomena into which they enter.

In our present inquiry, then, I mean to derive from attraction the help it offers in explaining the cause of elasticity; and I hope to make it evident, by a due consideration of attraction as common to all matter, and of the laws by which caloric constantly endeavours to maintain an equilibrium, not only among systems of bodies, but throughout each individual mass, that the efforts of these two, to maintain their respective powers over matter, and, in doing so, acting according to known and invariable laws, produce all those phænomena to which the term elastic has been applied, whether in solid or in aëriform substances.

I would say, then, that attraction, which pervades all matter, and caloric, which also pervades all matter, by their presence, and by an action in which both participate, occasion elasticity wherever it exists. Not that elasticity must follow as a necessary consequence of their presence, for then every substance in nature would be elastic, which many are not in the common sense of the word. Certain other conditions are necessary to elasticity; but without these two it could not exist.

It is admitted by all that attraction is the cause of the aggregation of the moleculæ of bodies. When the state of aggregation is such, that on the application of a given degree of mechanical force to the body the attraction of the moleculæ is overcome (or the body broken), it is called brittle : if the attraction is only partially deranged, the body will be found to have changed its form, and is then called flexible : when the body springs back, or, after certain vibrations, recovers its form, it is called elastic.

Many metallic bodies which are flexible in the sense just mentioned, may however by hammering be rendered elastic; that is, by merely bringing their moleculæ into more intimate union, or by bringing them reciprocally more within the spheres of each other's attraction. This is a circumstance which ought not to be lost sight of. Let us for a moment then inquire what takes place in the process, besides bringing the particles of the body more nearly into contact, or more of them into actual contact than were in that state before? When a bar of metal is hammered thinner than it was before, a quantity of caloric equal in volume to the diminution of volume imposed upon the bar has been expelled or driven out of it." I need not, however, insist on its being exactly equal in volume, as my present argument only requires that a certain quantity of caloric should 
be driven out of the mass by the operation, and I believe in the present state of our knowledge that few will be inclined to dispute it. As it is, however, of some importance to establish this point, I shall, before proceeding further with the main argument, briefly point out some of the circumstances which seem to prove the escape of caloric: The bar becomes heated by the operation, and where heat manifests itself, it must be either passing off from or into the body. If the capacity of the body be diminished at the same time, and the chemical properties of the body remain unaltered, which in the instance under consideration is the case, how can we mistake the direction in which the caloric moves?

I am aware of what has been advanced respecting friction by men whose names stand high in the philosophical world, and that hammering is a species of friction: but names and opinions should never be substituted for facts ; for, if it be true, which I deny not, but maintain that hammering is a species of friction, it would not be difficult to show that it is equally true that friction is a species of hammering. But if by hammering such a quantity of heat may be driven from the interior to the surface of a bar as will produce effects similar to those of a combustible body in a state of ignition, the caloric in this as in every other case must be something else than mere motion. It is subject to eertain laws of motion, like every other species of matter; and like every other species of matter too, when moved from its place by any force, putting other matter in the spare or spaces before occupied by it, it must take up another residence. To produce an accumulation of heat by hammering, repeated and a long continued succession of strokes are not necessary : proportion the mass of metal to the impulse to be applied, and with one stroke you may produce such a heat as will make the part of the metal where it is accumulated visible in the dark-hot enough to set fire to a combustible body.

It may here be also observed that heat is propagated even through what is usually called a vacuum, that is, through spaces absolutely void of every other species of matter, which could not possibly take place if caloric were not substantial; for motion is a non-entity when we attempt to conceive of it as distinct from matter-it is an accident of matter, and when we speak of its existence the presence of matter is always implied. This is an argument in proof of the substantiality of caloric which no powers of argument can overturn; for, whatever semblance of truth may attach

Vol. 92. No. 86. July 1805. K 
to reasnnings on motion as connected with matter, it vanishes entirely when the continuity of matter is broken, as in the case we have stated. But if in the case of the trans. nission of caloric through a vacuun, caloric is proved to exist independently of motion, why in any other ease should the two be confounded?

But to retuin.-A bar of metal by being hammered has a quantity of ealoric exprensed from it by mere mechanical means, without undergoing any chemical change. In other norrls, its capacity for holding caloric has hcen abridged, without its afinity for that substance being lessened; and the aggregation of the mass has been increased in a ratio bearing some proportion to the dimimution of its capacity for caluric.

When the hammer is first apphied to the metal, the latter is, comparatively speaking, plastic, and gives but little resistance; but as the parts are brought into a closer state of argregation the resistance increases, and the hammer recoils in proportion to the force with which it is applied and the degree of augregation the mass has acquited: in other words, the metal has acquired a dogree of elasticity proportioned to the time it has been sabjected to the mechanical process. It appears then that by dininishing the capacity of the metal for heat, while its natural affinity remains unaltered, it acquires the property of being elastic.

Let us attend a little to the case beforc us. When the metal bas received a certain degree of compression from the haunmer, it refuscs to receive more, and the hammer recoils; that is, by mechanical neans a certain degrec of caloric may be expressed from the metal, but as its affinity for caloric cannot be destroyed, the last portions of it cannot be expelled by any such process; and even a portion of what inay be expelled can only be momentarily separated, viz. enly during the continuance of the impulsc. It is this last eircumstance that occasions in the instance under examination an exhibition of what is called elasticity. That I may be the better enabled to convey my ideas on this point, I thall here call in the assistance of a figure to illustrate my meaning.

Let ABCD (Plate H. fig. 6.) be a mass of metal that has received all the density of which it is susceptible by bammering, or let it' be a mass (as an anvil) hardened by any other process, in such a manner that it can receive no. noom permanent compression from the action of a hammer. It a stroke of a hammer be applied on the surface $\mathbf{A B C}$. a momentary depression of the surface will take place, pro- 
portioned to the force that has been applied. Say that the curved line $\mathbf{A} a \mathbf{C}$ represents this depression, and the area $\mathrm{ABC} a$ its quantity: a quantity of caloric equal to the space $\mathrm{ABC} a$ is momentarily displaced by the blow.

But in this case an attempt is made to separate, by mechanical means, a portion of that caloric which the mass demands by its affinity; and this law, exerting itself to restore the equilibrium, takes back the quantity thus violently attempted to be taken away, and with such rapidity that the hammer is no sooner at $a$ than it is instantly pushed out by the reimbibed caloric. Nor is this all : caloric, being matter, must, when put in motion, obey the same laws that other matter would in similar circumstances. The reservoir that furnishes the supply (viz. the surrounding atmosphere) being inexhaustible, instead of the caloric ceasing to operate when it has brought the surface again to coincide with A B C, it carries it to $\hat{b}$, a distance as far above $\mathrm{B}$, or nearly so, as $a$ was below it ; and it is not till after repeated vibrations between these points that the surface at last comes to rest in its first position. Any one may satisfy himself of this fact by letting a hammer fall upon an anvil while he holds the handle easily in his hand; it will not give one but several strokes, proportioned to the force employed.

When the recoil of the stroke; as it is called, has carried the surface to $b$, why does not the mass retain the caloric (represented by the space $\mathrm{A} Z \mathrm{CB}$ ) which it has received by the effort thus made by its affinity for caloric? - Because the affinity of aggregation of the mass forbids it. The two affinities - that of the whole mass for caloric, and that of the molecula for each other-find their powers balanced when the surface comes to rest in the line ABC.

From what has been stated respecting the effect produced by the blow of a hammer on a hardened mass of metal, it will not be difficult to trace the effect that will follow if a soft bar of metal be interposed. We have seen that a quantity of caloric is momentarily expelled from a hardened mass of metal when struck by a hamnter, and as quickly reimbibed with an increase of quantity. When such a bar is struck on an anvil with a hammer, there is a displacement of the caloric from the part struck; and at the same time an increase in the aggregation of the molecula in the same part, that is, an increase of its elasticity. The quick return of caloric into the part makes the hammer recoil s but the mos lecule having been brought closer together by the blow, the ealoric finds less lodging toom than before, and of course an increase of temperature follows for the affinity of the 
mass for caionic is lessened as its moleculae are brought closer together. A second blow is followed by a like effect, which is in like manuer increased by succeeding blows. It is necessary, however, that these be given in such quick succession that the bar may not have time between to give off its caloric to surrounding bodies. If this be attended to, an accumulation of caloric must take place in the bar ; for by the second blow a larger quantity of heat is displaced than by the first, and consequently a larger quantity is imbibed to be affected by the third blow ; the quantity displaced by each blow being proportioned to that which was before present; and the quantity newly imbibed being proportioned to what was displaced by the last blow. This fact, with some latitude, will always be found to hold true. Need we wonder then at seeing a dexterous artisan lighting his forge without any other heat than what he can furnish to himself by means of his hammer and an iron rod?

In the casc which we have just examined the phænomenon appears to depend on the displacement of caloric in a body by an external force, while the affinity of aggregation endeavours to retain it. Will this be found to hold in other cases?-Yes, making allowance for the difference of circumstances.

Let AB (fig. 7.) represent a spring of stecl or any other metal. By'any external force let it be bent into the form CD. It is plain that one side of the spring has been elongated and the other shortencd.

But the spring before flexure had its moleculæ respectively at those distances or in that arrangement in which they best balanced each other; that is, the mutual effort of all was to keep the spring in the state it exhibited before any external force was applied; and the quantity of caloric resident in the mass was distributed throughout in proportion to the affinity of all the parts.

Let the proportion of caloric proper to any part of the mass in any common temperature be represented by the space comprehended between the two parallel lines $a b$ and id.

When the bar is bent, the lines $a b$ and $c d$ are made to approach each other, as at $e$ on the concave side, and to recede on the convex side, suppose to $f$ and $g$, so that they no longer remain parallel. In other words, a quantity of caloric has been displaced from the one side, and has found lodging-room in the other side of the bar; and what is said of this is understood of every other part of the spring. But the affinity of all the parts for caloric having undergone no 
change, it is plain that when the external force is removed it must resume its first position in the mass, and, by doing so, restore it to its former figure, in effecting which the atfinity of aggregation co-operates; for we have been supposing such a force only applied as could change the form, while applied, without overcoming the aggregation of the mass.

The vibrations which follow, if the spring be left quite free after force has been applied, may be explained in a way perfectly similar to what we have already laid down when speaking of a bar struck by a hammer. The caloric being put in motion, a larger quantity of it runs from the plus side to the side that was minus than the affinity of the latter demands, and is therefore driven back again, and so alternately, till by little and little it ceases its motion as equilibrium comes to be established.

After the bar A B has by any applied force been brought into the form $C D$, the caloric, which in the natural state of the bar resided between $l$ and $d$, having been forced to find lodging-room towards $a c$ on the side now rendered convex; and the lines $a b$ and $c d$, or the portions of metal which they represent, being brought into contact in the point $e$; or, if the possibility of the perfect contact of the moleculæ be denied, as nearly into contact as possible in the point $e$; then the said point $e$ (and so of any other point of the concave surface) bccomes a fulcrum over which the bar may be broken if an increased force be applied; for all the caloric that can be removed by mechanical means from the concave side having been transferred to some more convex part of the bar, it must follow, as a consequence, that any attempt to make the metallic matter enter spaces already occupied by metallic matter must be vain, and can only operate to draw the molecula on the convex side to such a distance from each other as to admit foreign matter between them, viz. the atmosphere or other surrounding medium, after which it will be impossible for them to coalesce again.

In this way would we account for that effect which has hitherto been ascribed to the molecula being removed to such a distance from each other as to place them beyond each others sphere of attraction. It is true they are brought into such a situation that their attractive affinity cannot again unite them as an aggregate; but we think their attraction is not annihilated, as the common mode of expression may suggest to those who do not properly examine the matter. There is anly a new affinity brought into plav, K 3 
viz. that of the metallic molecula for the newly interposed body; for, could that new affinity be destroyed, or, in other words, could the interposed substance be entirely removed, it is probable the affinity of the moleculx would again be exerted. Of this some idea may be formed by attending to what takes place when two spheres of lead, a little flattened, are pressed together. In proportion as the air has been excluded will be the adherence of the two balls.

We would not wish, however, to be understood to assert that in every case a disjoined mass would unite but for the newly interposed substance, for several conditions are requisite to this effect which can rarely exist, Among these may be mentioned, that there should be no new arrangement of portinns of the broken surfaces by the metal having by its tenacity drawn itself out into fibrous ligaments and protrusions; for in that case the points of contact upon joining the masses are so limited that the very weight of either part, that is, its gravity for the common centre of attraction, will act as a sufficient force to destroy the affinity which exerts itself to keep them united. We may also here remark, that in the confused crystallization of melted masses of metal, some of the portions mav always be conceived to be under some restraint, as it were, and this must hold also after the metal has been hammered. Therefore on breaking the mass some of these will always protrude, or in some way or other change their position a little, so as to produce an effect similar to that before described-reducing to a comparatively small number the points that can be brought into contact. Therefore what we mean to suggest is only this-that if every interposed substance could be entirely removed, and it were possible to bring the original number of points into contact, the affinity of aggregation would act to unite the parts of the mass.

I might apply the reasoning employed in the case of the spring AB to other cases of solid bodies; but, from what I. have said, I think any person may apply my reasoning in the same way as I would myself, whether he be convinced of its truth of not; to enlarge further appears therefore unnecessary. It is proper, however, that I should endeavour to show how the same doctrine applies to aëriform fluids.

When air is compressed, on removing the force it regains its first volume. This, however, is conditional. If the compressed air be of a given temperature, say $80^{\circ}$, and if it be afterwards reduced to a lower temperature, say $32^{\circ}$, it may so happen that the diminution of volume by reduction of temperature inay more than counterbalance the compressing 
pressing fotce that was employed. In this care, then, a mere abstraction of caloric annihilates a certain quantity of elastic force which belongs to the air when the common temperature is higher.

Again : Inclose a given quantity of air, not compressed, in any proper vessel, when the common temperature is $30^{\circ}$, and it will be found when the temperature becomes high, say $80^{\circ}$, that it has acquired an elastic force which it had not before.

The cause is obvious. The air inclosed at $30^{\circ}$ has as strong an affinity for caloric when the common temperature comes to $80^{\circ}$ as the air not inclosed, but is prevented by want of room from satisfying itself + the extent of its affinity. On opening the vessel, however, the caloric finds an easy admission; the volume of the mass becomes increased, and a quantity equal to this increase discharges itself.

But when by force we compress air which is to be again liberated without waiting for any remarkable change of temperature, we only accomplish by mechanical means what nature effects by a mere change of temperature. We express a certain quantity of caloric from the air, while its affinity for that substance remains undiminished. Remove the restraint, and, the affinity exerting itself, a sudden increase of volume takes place, exhibiting that phenomenon which is usually called elastic force.

Again: When a foot-ball is struck (and so of similar cases) there is a displacement of caloric proportioned to the force applied and the nature of the covering. But this is only momentary ; for, the affinity of the air for caloric remaining unaltered, a quantity of the latter, more than equal to what was displaced by the blow, is, for the reason before pointed out, instantly taken in by the air, and with such rapidity as to cause the ball to recoil from the foot in the same manner as a hammer does when struok on an anvil, but in a much more remarkable degree; for the recoil will always be proportioned to the force employed, compared with the affinity of the bodies for caloric.

Before concluding, we may observe generally, that every body in nature may be considered as in some measure elastic, though many of them cannot manifest that property to the extent which those bodies usually called elastic can; that is, a certain force may be applied to all of thern with. out destroying their form, and by the application of that force a certain quantity of caloric may be first accumulated in and then given of from them. In every case of this kind (and they include every species of friction) caloric is 
first expressed from, and then imbibed, with a surphs quantity, into the parts of the body which undergo the mechanical action, and it is this circumstance which has so much puzzled some philosophers in certain experiments on friction. But as we may possibly lay before the society at a future period a few thoughts confined principally to this object, we forbear entering further into it at present.

XXIII. On the Production of Muriates by the Galvanic Decomposition of Water: with a second Letter on the Sulject from Mr. W. PEEL, of Cambridge.

I

$I_{N}$ our last volume, page 279 , we laid before our readers a letter from $\mathrm{Mr}$. Peel, of Cambridge, announcing the production of muriate of soda by the Galvanic decomposition of water. That communication we considered as extremely important, and we suggested that such experiments as Mr. Peel was engaged in, might possibly lead to some knowledge of the composition of soda and the base of the muriatic acid.

The letter alluded to was dated the 23d of April last, and published in our number for that month. We have been not a little gratified since in finding that our suspicion has been in some degree confirmed by $M$. Cuvier's report of the labours of the Class of the Mathematical and Physical Scienees of the French National Irstitute from the 20th of June 1804 to the 20th of June 1805, published on the 25th of the last-mentioned month *. One of the articles of this report states, that M. Pacchiani, of Pisa, has discovered the radical of the acid in question, which he states to be hydrogen. By taking from water, by means of the Galvanic pile, a portion of its oxygen, he asserts that the water was converted into oxymuriatic acid; and that, consequently, "muriatic acid is hydrogen at its minimum of oxidation + ; the oxymuriatic acid, hydrogen in the middle state; and water, hydrogen at its maximum of oxidation."

The following letter was intended for our last number, but did not reach us in time. It will be found as interesting to our philosophical readers as Mr. Peel's former communication. The result of his new experiment, so far as

- Part of this report is given in our present Number.

+ In our 6 th vol. p. 153, we announced that Girtanner maintained hydrogen to be the radical of the muriatic acid, and that this acid contained less oxygen than water. 